\title{
Los códices Techialoyan y su censo: problemática sobre su número actual
}

\author{
Nadia Mariana SERralde Narváez y Miguel Ángel Ruz Barrio \\ El Colegio Mexiquense, A.C. \\ nserralde@cmq.edu.mx miguelruz@hotmail.com
}

Recibido: 23 de octubre de 2014

Aceptado: 15 de noviembre de 2014

\begin{abstract}
RESUMEN
En este artículo proponemos una revisión del número de códices Techialoyan que conocemos en la actualidad. Para ello partimos de una breve definición de este corpus documental creado entre finales del siglo XVII y principios del XVIII. En torno a estos manuscritos ha existido controversia desde los primeros estudios hasta la actualidad y todavía falta mucho por trabajar en su análisis. En nuestro caso, como paso previo al mismo, presentamos un examen de los listados y catálogos conocidos hasta la fecha con el objeto de ver las modificaciones que ha sufrido el grupo. La conclusión a la que llegamos es que era necesario replantear su número, ya que hay documentos fragmentados y otros desconocidos o que son copias. Por ello, el número es inferior a los 56 que aparecen catalogados hasta el momento.
\end{abstract}

Palabras clave: Códices Techialoyan, códices mesoamericanos, fuentes etnohistóricas, Nueva España, Centro de México.

\section{The Techialoyan Codices and their Number}

\begin{abstract}
In this article, it is proposed a brief revision of the number of Techialoyan codices. To do this, the text starts with a definition of the corpus, that it is composed of manuscripts done between the half of the 17th century and beginning of the next. Around these documents there are many doubts and it remains much to do. In this case, we present a review around the lists and catalogues to see the changes of the group through time. Our conclusion is that is necessary recount the corpus, because there are fragmented documents and others are unknowns or copies. Finally, we show our count, that leaves the number less than fifty-six documents catalogued until today.
\end{abstract}

Key words: Techialoyan codices, mesoamerican codices, ethnohistory sources, New Spain, Center of Mexico.

Sumario: 1. Introducción. 2. Los codices Techialoyan. 3. Censos, clasificaciones y lista de los codices Techialoyan. 4. Revisión del número de los Techialoyan. 5. Conclusiones. 6. Referencias bibliográficas.

\section{Introducción}

Tras la conquista española, en el Centro de México continuó la producción de los manuscritos pictográficos conocidos como códices mesoamericanos. Mientras que muchos documentos prehispánicos acabaron destruidos o perdidos, las autoridades coloniales y personas particulares favorecieron que la creación de códices no desapareciese. Actualmente el número supera ampliamente los quinientos, por lo que su clasificación ha sido una necesidad ya que facilita su estudio y análisis.

La propuesta más aceptada ha sido la de John B. Glass (1975a) en el Handbook of Middle American Indians (en adelante: HMAI) que se aplicó en el censo que se incluía en dicha publicación de cada uno de los grupos propuestos. Esta clasificación es muy significativa, ya que nos ilustra sobre la variedad de informaciones que nos proporcionan estos documentos. Si bien algunos autores han señalado que se hace 
necesaria una revisión (véase Batalla 2008: 202-205), en realidad se ha ido reproduciendo sin más en muchos trabajos. Asimismo, la actualización del censo se encuentra disponible en Wiki-Filología (s.f.) y en líneas generales respeta la clasificación de John B. Glass (1975a). Esta se creó entre finales de los años sesenta y principios de los setenta del siglo XX gracias a la colaboración de los especialistas de aquella época en esta documentación. Hay que señalar que se enfrentó a varias limitaciones marcadas por el momento en que se realizó, como la falta de estudios de muchos documentos o el difícil acceso a reproducciones fotográficas. Sobre estas bases, Glass (1975a) propuso un primer nivel en el que distinguía cuatro grandes grupos con características propias y que se definieron en sendos censos independientes en el HMAI:

1) En general (Glass y Robertson 1975): como indica su título era un conjunto amplio en el que en realidad se recogían los códices mesoamericanos propiamente dichos, mientras que los otros tres engloban documentos muy particulares que no pueden ser considerados como tales.

2) Testerianos (Glass 1975b): se trata de un grupo de manuscritos pintados en época colonial sobre papel europeo, cuya característica es la utilización de un sistema pictográfico para contener la Doctrina y el Catecismo cristianos.

3) Códices falsos (Glass 1975c): son documentos que intentaron pasarse por originales, con una intención lucrativa, pero que pueden tener una cierta importancia (véase Batalla 2006). Entre otras cosas, su existencia demuestra el enorme interés, no sólo cultural, que este tipo de documentos despierta.

4) Techialoyan (Robertson 1975) ${ }^{1}$ : reciben el nombre del Códice de San Antonio Techialoyan, datándose entre finales del siglo XVII y principios del XVIII.

Este último conjunto es muy particular y ha despertado un gran interés a partir de los años cuarenta del siglo XX, cuando comenzó su estudio. Durante este tiempo, al igual que en los otros grupos, han ido apareciendo nuevos documentos y por ello continúa aumentando su catálogo. Sin embargo, una revisión superficial de todos ellos demuestra que hay algunos aspectos que no encajan y por ello hemos decidido presentar este trabajo. Para llevarlo a cabo, vamos a comenzar por definir qué son los códices Techialoyan y cuáles son sus características, lo que nos permitirá después repasar y analizar los distintos listados y censos realizados de ellos. Finalmente, plantearemos cuál es nuestra propuesta sobre el número de los Techialoyan que se conocen en la actualidad.

\section{Los códices Techialoyan}

\subsection{Definición}

La denominación de códice Techialoyan se remonta al estudio en los años treinta del siglo XX de un documento que se encontraba resguardado en la Biblioteca del Museo

1 Si bien el trabajo que introduce al censo fue obra de D. Robertson, el catálogo lo realizó junto a Martha B. Robertson. Debido a que el capítulo aparece sólo con la autoría del primero, hemos decidido incluirlo de esta manera en la bibliografía. 
Nacional de Antropología (México) por Federico Gómez de Orozco (1933). Hasta ese momento se desconocía su lugar de procedencia y no tenía un nombre específico. Por ello, en su trabajo Gómez de Orozco (1933: 313), tras analizar el contenido y la información que presentaba, expuso que «[b]ien podría llamársele Códice de Techialoyan, por ser ésta la población principal allí registrada»; proponiendo además que este lugar era un poblado ubicado en el Estado de México.

El descubrimiento del códice de San Antonio la Isla ${ }^{2}$ fue clave para definir el grupo de los Techialoyan, debido a que se localizaron documentos que compartían algunas de sus características. Antes ya se conocían algunos que pasarían a englobarse en este corpus, como el Códice de Cempoalla publicado por Bernard Quaritch (1890). El problema es que tanto este autor como Gómez de Orozco fechaban estos códices alrededor de 1530 (Gómez de Orozco 1933: 312-313; Quaritch 1890). Como señala H.R. Harvey (1986: 154), debido al material empleado y su deterioro, muchos los habían considerado como más antiguos, lo que provocó su circulación por las manos de diversos coleccionistas.

Finalmente, el término Techialoyan fue asignado al grupo por Robert H. Barlow (1943). Esta es una palabra náhuatl que, según el diccionario de fray Alonso de Molina (2013 [1571], 23: 92r) significa «mesón», al igual que techialcalli. Nadine Beligand (1993: 43-44) realiza un análisis etimológico más profundo y señala que se refería al «lugar donde se espera a alguien». Actualmente, la denominación de códice o códices Techialoyan se emplea para referirse a una serie de documentos que tienen características en común como el soporte de papel amate, el tipo de letra, el estilo pictórico, las imágenes, la temática y el contenido. Stephanie Wood (1998: 167) los ha definido como «documentos gráficos comentados, que datan del siglo XVII o XVIII, son registros escritos en náhuatl (...) que ilustran y describen sucesos y límites físicos de las comunidades indígenas en la época de la pre y la postconquista». Veamos con detalle qué define al grupo.

\subsection{Características generales del corpus}

Como se advirtió anteriormente, los códices Techialoyan fueron elaborados entre finales del siglo XVII y principios del XVIII, y se vinculan con poblaciones del Distrito Federal, Estado de México, Hidalgo, Tlaxcala y Morelos (Martínez García 2007; Noguez y Martínez García 2009; Wood 2007).

El soporte de estos documentos es uno de los elementos que han servido para clasificarlos. La peculiaridad es el uso de papel de amate en bruto en libros de formato europeo, aunque hay alguna presentación diferente como veremos a continuación. El material empleado se distingue del utilizado durante el siglo XVI por ser más grueso y presentar distintos tonos café obscuro (Robertson 1975: 254). Para su elaboración no se aplicó la imprimatura de cal, como en el caso de los códices de la época prehispánica y algunos coloniales, como el Códice de Santa Cruz Tlamapa número 1, por

\footnotetext{
2 Este es el nombre actual de San Antonio Techialoyan.

3 Distinguimos como 1 el Vocabulario en lengua castellana/mexicana y como 2 el Vocabulario en lengua mexicana/castellana.
} 


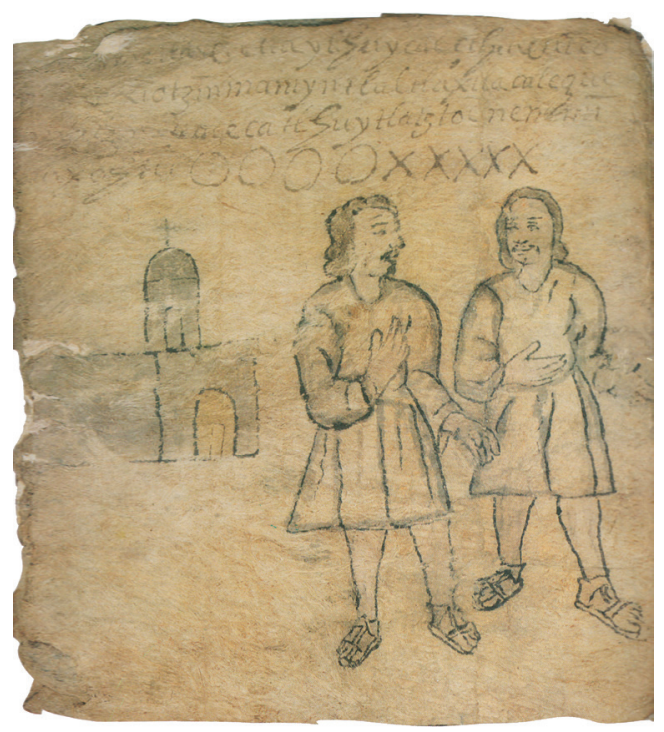

Figura 1: Folio 6v del Códice de San Pedro Tototepec (Noguez 1999).

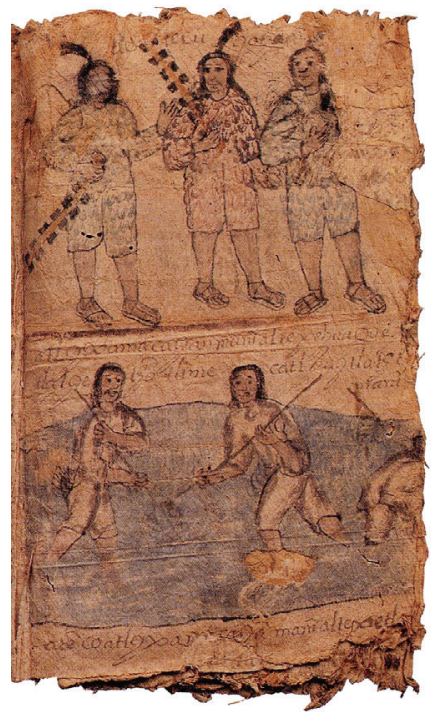

Figura 2: Página 11 del Códice de Coyotepec (Fane 1996: 81).

lo que con el paso del tiempo se ha ido deteriorando: las hojas de muchos documentos muestran pérdidas en los bordes y en algunos casos han desaparecido fragmentos completos.

Se han establecido tres formatos para estos códices. El primero, y más común, es el de hojas simples o reunidas en un doble folio o la combinación de ambas que forma un libro europeo. El segundo es el de panel, el cual se encuentra por ejemplo en los códices de Atlapolco $(74 \times 94 \mathrm{~cm})$ y Coyotepec $(74$ x $96 \mathrm{~cm})$. La tira, el tercer y último tipo, consiste en una larga superficie de amate, que se usó en el Códice García Granados, un documento particular considerado dentro del conjunto (Noguez 1992; Robertson 1975: 255) que, como veremos a continuación, nosotros excluiremos del mismo. Debido a ello, en nuestra opinión sólo se debería hablar de dos formatos: libro europeo y hoja suelta de gran tamaño.

Los colores empleados fueron el azul, verde, amarillo, naranja, rojo, blanco, gris y negro y su aplicación en los códices busca en algunos casos resaltar las sombras en los pliegues o drapeados, aunque no se puso sombra debajo de las figuras humanas, ni de las construcciones (Robertson 1975: 255 y 261).

Uno de los elementos más característicos de los Techialoyan es su estilo gráfico y pictórico. En general, según R. Martínez García (2007: 37), se puede decir que presentan un mayor número de elementos de la plástica europea que de la convención nativa. Ha sido D. Robertson (1975) quien más se ha ocupado de las características de su estilo y por ello debe ser nuestro punto de referencia.

En cuanto a las pinturas, se pueden enunciar varios aspectos señalados por Robertson (1975). En primer lugar, las hojas pueden incluir una (Figura 1) o dos escenas (Figura 2). En segundo, en el paisaje se intenta reflejar la tridimensionalidad (Robert- 
son 1975: 260). En tercero, Robertson (1975: 260-261) advierte que la mayoría de las figuras humanas parecen ser idénticas y de forma alargada (Figura 3). Los hombres se representan con vestimenta de tilma o de piel de animal, portan arcos o flechas, macanas, lanzas, escudos. Las mujeres se presentan con vestidos de piel (Figura 4) o tela (Robertson 1975: 261-262). En cuarto, la línea de contorno se caracteriza por ser ancha, a diferencia de la usada en la época prehispánica.

Respecto a los textos, en su mayoría en lengua náhuatl, se caracterizan por ser similares en casi todos los documentos. El vocabulario empleado es limitado, pues en comparación con el náhuatl del siglo XVI se usan pocas palabras. En algunos casos se recurre a crear términos en lengua indígena, cuando se usaba de manera habitual el préstamo (Wood 2007: 12-16). Además, las construcciones gramaticales son sencillas, predominando los enunciados cortos. La escritura es muy similar entre los códices, por lo que se llega a hablar de «grafía techialoyan». El tipo de letra que integran las glosas son minúsculas, redondas y de tamaño amplio, además las palabras no están separadas en el texto (Martínez García 2007: 20). Sólo algunas letras

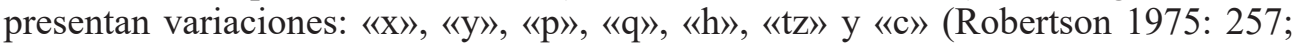
Wood 2007: 7-8).

El contenido de los códices es muy específico: el texto busca definir los límites territoriales de una determinada comunidad (Batalla 2005: 22). Para ello, se hace referencia a la historia prehispánica y colonial, junto a la descripción de las tierras y linderos (Robertson 1975: 255). En la parte histórica, se menciona a los ancestros, los caudillos, la nobleza, la conquista española, la evangelización, el bautismo, las autoridades civiles y la elección del santo patrono (Noguez 1999: 39). En la enumeración de las tierras del pueblo y los linderos, se expresan las unidades de medida (Martínez García 2007: 21).

Respecto a las fuentes que se emplearon para la realización de los Techialoyan, S. Wood (1998: 190-194) ha propuesto que quienes elaboraron estos documentos pudieron haber consultado o visto documentación como los Cantares Mexicanos, la Historia Chichimeca de Fernando de Alva Ixtlilxóchitl, además de informes y crónicas de los jueces indígenas, junto con fuentes españolas.

Todas estas características han permitido delimitar un grupo particular de códices. Dicho corpus ha ido creciendo, pero, como ya hemos dicho, no sabemos realmente cuántos hay en la actualidad ni cuántos pudo haber.

\section{Censos, clasificaciones, catálogos y listas de los códices Techialoyan ${ }^{4}$}

En el presente trabajo, nos hemos propuesto hacer una revisión de la evolución de la clasificación y catalogación de este corpus; para ello hemos elaborado el Cuadro 1, al que haremos referencia a lo largo de este apartado. En la primera columna se recoge,

\footnotetext{
4 Censo: «Padrón o lista de la población o riqueza de una nación o pueblo» (DRAE 2012). Catálogo: «Relación ordenada en la que se incluyen o describen de forma individual libros, documentos, personas, objetos, etc., que están relacionados entre sí» (DRAE 2012). Clasificación: «Relación de los clasificados en una determinada prueba» (DRAE 2012). Lista: «Enumeración, generalmente en forma de columna, de personas, cosas, cantidades, etc., que se hace con determinado propósito» (DRAE 2012).
} 


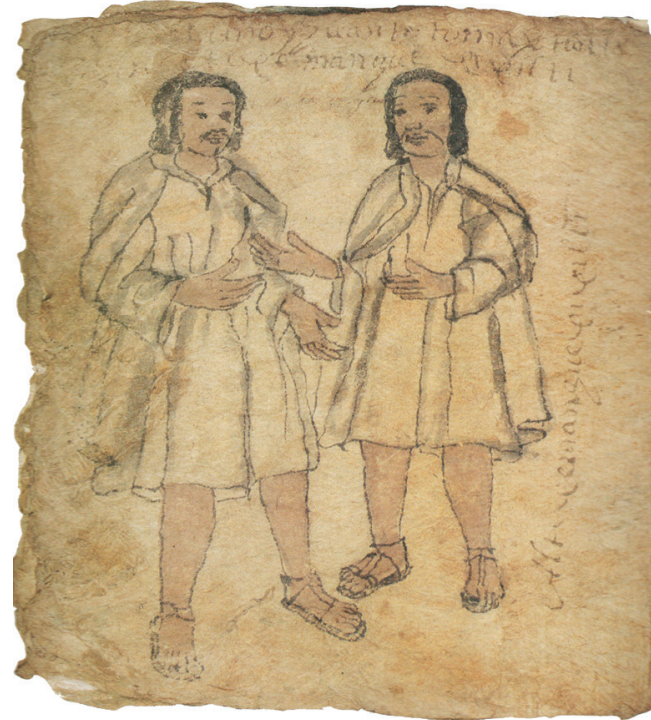

Figura 3: Folio 8v del Códice de San Pedro Tototepec (Noguez 1999).

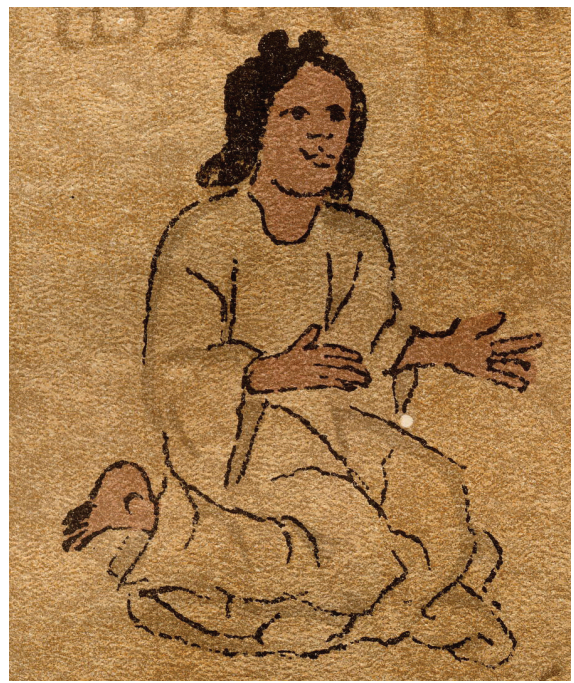

Figura 4: Detalle del folio 8v del Códice de Cempoalla (Quaritch 1890).

por norma general, el nombre del códice comenzando por el topónimo náhuatl del pueblo al que se refiere. Las siguientes se han organizado por orden cronológico de acuerdo a los recuentos o clasificaciones que se han efectuado de los documentos. Partimos del trabajo de F. Gómez de Orozco (1933), aunque no constituye un censo propiamente dicho. Lo recogemos debido a que fue tomado como referente para la elaboración del primero, el de Barlow (1943: 161-162). En el resto de columnas recopilamos las adendas que fue realizando Barlow (1944, 1947a, 1947b, 1948 y 1949; Barlow y McAfee 1946), junto a las propuestas de Gómez de Orozco (1948) Robertson (1959 y 1975) y Noguez y Martínez (2009). Por último, incluimos nuestra propuesta a partir de la revisión realizada.

Pasando al repaso propiamente dicho, fue Gómez de Orozco (1933: 311-314) quien comenzó a prestar atención a las similitudes entre el Códice de San Antonio Techialoyan y diversos documentos, que eran los siguientes: San Pablo Huyxoapan, San Pedro Cuajimalpa, Metepec, Cempoalla ${ }^{6}$, Ixtapalapan, fragmento perteneciente al señor Jorge Enciso ${ }^{7}$ y otros dos que fueron vistos por José María Agreda y Sán-

\footnotetext{
5 Resulta confuso a quién atribuir este listado. En la recopilación de obras completas de Barlow, se le adjudica a él (Barlow 1994 [1948]). Sin embargo, el texto que introduce el apéndice no lo deja claro, ya que dice: «Lista de los códices del Grupo Techialoyan, formada por Roberto H. Barlow, quien los ha venido citando con letras de la manera que sigue» (Gómez de Orozco 1948: 65). En este estudio, optamos por considerar que fue Gómez de Orozco el autor, porque esto nos permite comprender algunos errores y omisiones del listado. Además, otros autores como Robertson (1959) también le atribuyen la autoría.

6 Conocido por la publicación de Quaritch (1890).

7 Gómez de Orozco (1933: 331-332) incluye la traducción realizada por Mariano J. Rojas de este fragmento.
} 
chez. No se trataba de un censo como tal, pero era la primera vez que se establecía una posible vinculación entre estos códices.

A partir de este trabajo, como hemos visto, fue R.H. Barlow (1943) quien planteó la existencia de un corpus Techialoyan y lo ordenó en un listado, en el que asignó letras a los documentos. Ocho son los códices registrados: A. San Antonio la Isla, B. San Pablo Huyxoapan, C. San Pedro Cuajimalpa, D. Códice de Metepec, E. Cempoalla, estado de Hidalgo, F. Ixtapala, G. Pueblo no identificado, códice del señor Enciso y H. Códice de Santa María Zolotepec u Ocelotepec ${ }^{8}$.

Tras esta propuesta, Barlow se dio a la tarea de publicar la noticia de varios documentos, añadiendo la letra correspondiente al orden de aparición. En 1944, menciona el códice «J», el de Santa Cecilia Acatitlán (Barlow 1944: 232). Dos años después saldría a la luz el Códice de Santa María Calacohuayan, «K» (Barlow y McAfee 1946). En el siguiente año se registraron el «L» y «M», San Miguel Mimiahuapan y San Bartolomé Tepanohuayan, respectivamente (Barlow 1947a y 1947b). El «N», Santa María Tetelpan, fue integrado un año más tarde (Barlow 1948) y el «P», correspondiente a Tepozotlan, el último al que se refirió Barlow (1949).

Paralelamente, Gómez de Orozco (1948) publicó un trabajo sobre el estilo de los Techialoyan, al que acompañaba un apéndice con las letras que había dado Barlow ${ }^{9} \mathrm{y}$ agregaba nuevas, alcanzando un total de 19 documentos a los que añade noticias de otros de los que no tiene suficiente información. En su listado, mantiene el uso de las letras del abecedario, que van de la «A» a la «V $»$, aunque se omiten la «I» y la «O»» para evitar la confusión con el numeral romano y arábigo respectivamente. En esta lista hay algunas inconsistencias (véase Cuadro 1), como la omisión del «N», correspondiente al de Santa María Tetelpan, que ese mismo año había registrado Barlow (1948). Además, el códice «M» para Gómez de Orozco (1948: 66) es el de Coyoacan, cuando esta letra correspondía al de San Bartolomé Tepanohuayan de acuerdo con Barlow (1947b). El documento registrado como M podría ser el N, teniendo en cuenta que Robertson (1975: 269-270) señala que éste se encuentra en la John Carter Brown Library, dando como segundo nombre «Codex Coyoacan». Además, el lugar al que pertenece está cerca de Coyoacán (Barlow 1948: 284).

Olvidando estos detalles, los nuevos códices que registró Gómez de Orozco (1948: 65-67) son: «P». el fragmento de un libro de pueblo (Tepotzotlan); «Q». García Granados; «R». Códice de Chalco; «S». Azcapotzalco; «T». Tepozotlán: «U». de un pueblo cercano de Huehuetoca; y «V». Códice de San Cristóbal Coyotepec.

Desde entonces y hasta 1959 no hemos localizado nuevas revisiones del listado de Techialoyan. Es en ese año, cuando D. Robertson (1959: 190-195), dentro de su obra general, dedica un breve capítulo a los Techialoyan. Una de sus aportaciones es que integra a la cuenta el Códice de Xonacatlán o Códice Techialoyan de Tulane, aunque no le asigna una letra (Robertson 1959: 190, notas 4 y 5).

Más tarde, en colaboración con Martha B. Robertson, Donald Robertson (1975) realizó un catálogo extenso de este grupo que fue publicado en el $H M A I$, donde se registraba un total de 48 entradas, en este caso con un número del 700 al 748 . Este

8 En el catálogo de Robertson (1975: 268) aparece sólo como Ocelotepec, al igual que en la adenda de Noguez y Martínez García (2009).

9 Véase nota 7. 
trabajo proporciona al lector diversa información: el lugar de procedencia y el repositorio donde se encuentra, una breve descripción física del códice y referencias bibliográficas en las que se hace mención del mismo. En el listado se incluyen los murales de la catedral de Cuernavaca, Morelos, por presentar similitudes con el estilo pictórico de los Techialoyan (Robertson 1975: 262-263, 279).

El número fue aumentando en años posteriores y para 1992 y 1993 se contabilizaban alrededor de 54 (Harvey 1993: 51; Noguez 1992: 7). En 1994 se tuvo noticias de un códice procedente de San Pedro Tototepec que se publicó y se agregó a la lista (Noguez 1999: 11-12). En la actualidad, el censo más actualizado con el que se cuenta es una adenda al trabajo de Robertson (1975) elaborado por X. Noguez y R. Martínez García (2009), que se puede consultar en Wiki-Filología, donde registran un total de 56. Tal y como señalan en su introducción, el objetivo era completar y poner al día el trabajo de Donald y Martha B. Robertson. Entre los elementos que destacan del corpus, está el hecho de que el número de códices Techialoyan ha ido creciendo desde su definición y que éste es un problema que debe ser explicado. Sin embargo, no llegaron a plantearse una revisión de algunas inconsistencias que venían de tiempo atrás en el catálogo (véase Cuadro 1).

Más tarde, los propios autores de la adenda al catálogo de Robertson han planteado la necesidad de reconsiderar el número de códices. Este es el caso de R. Martínez García (comunicación personal, 16/12/2014), para quien deberían estar entre 43 y $42^{10}$ ejemplares, aunque no aporta una explicación razonada de ello.

Por ello en nuestra opinión, el número de documentos del corpus Techialoyan también debe ser revisado y de ahí la realización de este trabajo. Las causas de esto son diversas. Por ejemplo, hay manuscritos que no son del grupo, debido a que no comparten todas las características que lo definen, pero que se incluyen en él. Este el caso del Códice García Granados, debido a que su contenido es totalmente distinto al de los Techialoyan como ya indicaron quienes los estudiaron (Noguez 1992). Asi, J.J. Batalla (2008: 218) afirma que:

«Personalmente, debido a su contenido hemos dejado de considerar hace mucho tiempo este documento como perteneciente al grupo de los códices Techialoyan, pues lo que los une realmente es el personaje que se encontraba detras de todos ellos (...), y el estilo que utilizaba en su realización (...) Por ello lo que realmente une a los Códices Techialoyan y a los códices García Granados, Azcatitlan y Cozcatzin es sobre todo el estilo pictórico, pues debieron ser realizados en el mismo taller donde se reproducían todo tipo de documentos 'antiguos' a petición de los interesados en ellos».

Nosotros consideramos, teniendo en cuenta no sólo esta postura sino también el estudio del documento (véase Noguez 1992), que el Códice García Granados no debe incluirse dentro del corpus. Es decir, no es un Techialoyan, porque no cumple con todas las características que los definen. Sin embargo, no debe olvidarse de cara al estudio conjunto por la vinculación de todos ellos con don Diego García de Mendoza Moctezuma (véase Castañeda 2009; Wood 1998).

Además, hay códices Techialoyan que con el paso del tiempo se fragmentaron y han ido a parar a distintos lugares; sin embargo a la hora de contabilizarlos no

10 Plantea estas dos cifras en función de contabilizar o no el Códice García Granados dentro del grupo. 
deberíamos considerar que son independientes. El propio Martínez García (2011) explica, por otro lado, que cuando se hizo la adenda al trabajo de Robertson (1975) se detectaron algunas inconsistencias, como la inclusión de los murales de Cuernavaca, los cuáles no corresponden al estilo Techialoyan, como lo había advertido en algún momento el propio D. Robertson. Sin embargo, decidieron no modificar lo que ya estaba hecho, aunque crea una cierta confusión y por ello hemos decidido realizar esta revisión.

\section{Revisión del número de Techialoyan}

Nosotros no estamos de acuerdo con el número de códices registrados por varias razones. En primer lugar, creemos que en el censo hay documentos que no debieron haber sido incluidos, pues no cumplen las características que definen al corpus. En segundo, no se contemplaron datos que ya planteaban dudas sobre los documentos o la posible unión de varios.

Como acabamos de señalar, ya se ha hablado de algunas incoherencias en el catálogo. R. Martínez García (2011) resalta el caso de dos códices que están fragmentados: San Pablo Huyxoapan y Tepotzotlán. Del Códice San Pablo Huyxoapan, Martínez García (2011) explica que existen tres registros: $(702)^{11}$, (717) y (735) ubicados en distintos repositorios ${ }^{12}$, pero que conforman un único documento. Cuando Robertson (1975: 266, 271 y 276) elaboró el censo del HMAI hace la anotación de que estos fragmentos tenían afinidades en contenido y estilo, a lo que añade que presentaban la misma mano e idénticas dimensiones ${ }^{13}$. Gracias a ello concluye que, juntos, componen un manuscrito incompleto.

Respecto al segundo códice, Tepotzotlán, la situación es similar, es decir hay tres registros (714), (718) y (722) repartidos por repositorios diferentes ${ }^{14}$. Al igual que en el caso anterior, Robertson (1975) señaló que conforman un documento completo y además estableció su orden ${ }^{15}$. Sin embargo, estas anotaciones no fueron tenidas en cuenta en el momento de realizar el conteo de la adenda (Noguez y Martínez 2009), pues en los dos casos que acabamos de ver no se les da un único número.

Además de estos, hemos detectado otros registros que deben ser revisados para establecer el número de Techialoyan que conforman el corpus. Nos referimos, entre otros, al Códice de Metepec (704) y varios casos que presentan entradas diferentes para igual nombre: Códice de Coyotepec (727 y 747), Códice de Tizayuca (728 y 729), Códice de Tolcayuca (751 y 752), Códice de San Bernabé Ocotepec (753) y Códices Matlatzincas (739-741). Vamos a examinarlos uno por uno.

\footnotetext{
11 Incluimos entre paréntesis el número de catálogo que les dio Robertson (1975) o, en su caso, Noguez y Martínez García (2009).

12 En la Biblioteca Nacional de Francia hay dos folios (702), en el Museo Británico se resguardan cuatro (717) y en la Biblioteca Nacional de México otros cuatro (735).

13 El (702) tiene 45 x 22,5 cm; el (717) 46 x $24 \mathrm{~cm}$; y el (735) 45,5 x 21,75 cm. Las diferencias pueden deberse, entre otras cosas, al deterioro.

14 Diez folios están resguardados en la Newberry Library, Ayer Collection, Chicago (714), nueve en la Biblioteca Nacional de París (718) y seis en la John Rylands Library, Manchester (722).

15 En primer lugar coloca los nueve folios del (718) y a continuación los diez del (714) y los seis del (722).
} 
El Códice de Metepec fue registrado por Barlow (1943) bajo la letra D. Por su parte, Gómez de Orozco (1933: 328) señalaba que lo había visto «en poder del señor Antuñano» y que se componía de fragmentos procedentes de Metepec (Estado de México). Robertson (1975: 267), aunque lo mantiene en el catálogo, señala que está en paradero desconocido, información que se repite en la adenda (Noguez y Martínez 2009) a la que se añaden referencias bibliográficas que no aportan nada nuevo. Sí tenemos noticias de un título primordial procedente de ese lugar, catalogado como tal por P. López Caballero (2003: 131), el cual no tiene las características de un Techialoyan por tres motivos principales: el soporte es papel europeo, la grafía no es parecida y el documento no tiene similitudes en las imágenes (vid. Garibay 1992 [1949]). No sabemos si pudo ser este mismo manuscrito el que se catalogó como Techialoyan a partir de las noticias de Gómez de Orozco (1933), pero sí tenemos claro que es difícil mantener un documento del que no sabemos nada. Por ello, lo marcamos como perdido en el Cuadro 1.

Respecto al Códice de Coyotepec contamos con dos registros (727) y (747) en el catálogo de Robertson (1975: 273-274 y 279) relacionados con este nombre, por lo que podría tratarse del mismo documento. En el Museo de Brooklyn se resguardan 9 folios con unas dimensiones de $42 \times 26,8 \mathrm{~cm}$, registrados en el número (727). El (747) se corresponde con 10 folios ubicados en una colección desconocida. El propio Robertson (1975: 273) señala la posible relación entre ambos registros y también menciona que se debe consultar el (720), Códice de San Cristóbal Coyotepec (Robertson 1975: 272 $)^{16}$. Vamos a quedarnos con la posible relación entre el (727) y el (747). Robertson (1975: 279) afirma que la referencia a estos diez folios la toma de una fotografía de B. McAfee y considera tres posibilidades. La primera es que se tratase del mismo número (727) del Museo de Brooklyn, pero no coinciden en el número de folios, ya que el (747) tiene uno más; la segunda es que fuese un documento perdido y la tercera que se encuentre en una colección privada. El problema es que no hemos podido obtener más información. Una vía sería intentar consultar la colección McAfee ${ }^{17}$ para intentar localizar las fotografías que vio Robertson (1975). Mientras tanto, creemos que lo más adecuado sería quitar el Techialoyan (747) del recuento y dejarlo como perdido (véase Cuadro 1), debido a que Robertson, como acabamos de señalar, duda de su existencia.

El tercer caso es el Códice de San Salvador Tizayuca. Tenemos dos registros asociados con este lugar: (728) y (729). Ambos se encuentran en la Hispanic Society of America, Nueva York, y se diferencian porque el (729) se califica como mapa. Sin embargo, ambos están en el volumen 1 de los cuatro que componen el denominado Codex Kaska (Robertson 1975: 274). El (728) tiene 18 folios y el (729) es una hoja suelta de gran tamaño (Robertson 1975: 274). Existen dos copias de este último, una, al parecer de Francisco Tirso Rosales, resguardada también en la Hispanic Society of America, y otra en la Biblioteca Nacional de París (Robertson 1975: 274). Tanto el 729 como el 728, podrían formar parte de un conjunto documental y, por ello, nuestra duda radica en si por tener un formato distinto los debemos separar o, por el contra-

16 Este documento, de 74x96 cm, se encuentra en el Museo Nacional de Antropología, México. Christensen (1997: 252) considera probada su asociación de éste con el (727).

17 Se encuentra en la Charles E. Young Research Library de University of California, Los Angeles. 
rio, constituyen un único códice. Hemos optado por lo segundo, aunque es necesario un análisis minucioso.

El Códice de San Juan Tolcayuca (751) junto al denominado Mapa de San Juan Tolcayuca (752) presentan una situación similar a la anterior. Ambos se encuentran en la Colección Jay I. Kislak, de la Library of Congress en Washington, D.C. y se pueden consultar a través de Internet en la página de «The Mapas Project» ${ }^{18}$ a cargo de Stephanie Wood. Al provenir del mismo lugar, creemos que también podrían ser considerados como un mismo documento o expediente documental, al igual que en el caso de Tizayuca. Algo interesante es que algunas de las pinturas del (751) se alejan bastante de las de otros Techialoyan.

El quinto documento que queremos recoger es el de San Bernabé Ocotepec, número 753 de la adenda. No se conoce el original, sino una posible copia del siglo XVIII guardada en la sacristía del pueblo (Noguez y Martínez 2009). Es un lienzo de algodón con unas dimensiones de 160 x $200 \mathrm{~cm}$. Este no debe incluirse en el censo, ya que si bien tiene algunas reminiscencias del estilo de los Techialoyan es evidente que se trata, al menos, de una copia tardía.

Este códice y otros, como el ya referido de Metepec (704), nos llevan a plantearnos cómo debemos considerarlos. Es decir, tenemos muchos que son copias, pero no conservamos el original, y otros de los que sólo tenemos una referencia, en ocasiones vaga. Creemos que todos ellos no deberían estar en el censo de Techialoyan y tal vez crearse listados independientes, para no confundir, de ahí la diferenciación que planteamos entre los cuadros 2 y 3 . Respecto a los que tenemos sólo una noticia sin ejemplar, o una reproducción parcial, son: $(707)^{19},(719)^{20}$, y $(748)^{21}$. En cuanto a los que poseemos sólo una copia, encontramos los siguientes: $(742)^{22}$ y $(743)^{23}$.

El último caso que queremos resaltar es el de los códices Matlatzincas o de San Pedro Tzictepec (739, 740 y 741). De acuerdo con el censo revisado por Noguez y Martínez (2009), los tres registros parecen indicar que son uno sólo de 34 folios en total, aspecto que en el catálogo de Robertson (1975: 277-278) ya se advertía. En el HMAI se les nombraba como Teotla (739), Zepayahutla (740) y Tenancingo (741), si bien en todos se mencionaba al pueblo de San Pedro Zictepec o Tzitepec (Estado de México). En este caso también parece que hay un mapa con fecha de 1639 asociado a los tres fragmentos. Un problema es que, a pesar de afirmarse que son un documento

18 http://mapas.uoregon.edu/ (con acceso el 10/02/2015).

19 Este es el códice del señor Enciso comentado por Gómez Orozco (1933). De él tenemos una traducción hecha por Mariano J. Rojas.

20 Gómez de Orozco (1948: 67) señala que sólo se poseen copias fotostáticas de McAfee y que el original está en paradero desconocido. Por tanto, su situación es similar al (747) ya comentado.

21 Robertson (1975: 279) indica lo siguiente sobre este documento: «Mentioned in catalog notes of Brooklyn Museum Techialoyan 727, Coyotepec Coyonacazco (by Emilio Valtón?). Not found by Robertson in BAV in the winter of 1964-65». Debido a que estos ocho folios están desaparecidos y no localizados, hemos decidido no contabilizarlos como Techialoyan.

22 Robertson (1975: 278) señala que está perdido. Tenía un folio.

23 Este documento es una copia en papel europeo, probablemente del siglo XVIII. que está perdida (Robertson 1975: 278). El estilo de las imágenes en muchos casos difiere del de los códices Techialoyan, aunque en otros son muy semejantes por ejemplo a varias del Códice Techialoyan de Xonacatlán y, sobre todo, con el (704) de Cuajimalpa y el (718) de Tepotzotlán. Sin embargo, al ser una copia posterior sobre papel europeo hemos decidido no incluirla en el listado de códices Techialoyan. 
y ponerlos juntos, se mantiene la numeración. Esto provoca de nuevo el error de contar tres en lugar de uno para la suma total del corpus.

Considerando las anotaciones anteriores, proponemos que se eliminen del registro o se fundan en uno sólo los casos que hemos expuesto. Además, creemos que se tienen que excluir del censo los Murales de Cuernavaca, pues estos no presentan el estilo Techialoyan o al menos no son un documento del corpus. Nosotros proponemos que el censo total de los códices Techialoyan sería de 34 documentos que presentamos en el Cuadro 2. En la primera columna recogemos el nombre que debería darse, partiendo del lugar al que parece referirse. En algunos casos, este topónimo parece incuestionable porque el códice ya ha sido estudiado con profundidad pero en otros, de los que no disponemos de trabajos concretos, pensamos que se trata de algo sujeto a revisión. Es más, éste es uno de los factores que pueden crear confusión en el corpus, ya que no nos queda claro por qué se nombraron de determinada manera. No hay que olvidar que en estos documentos una parte clave del contenido son los linderos, por lo que pueden aparecer muchos nombres de lugar. Por otro lado, debemos señalar que la ordenación es alfabética y hemos desechado asignar un número o una letra que los identifique, porque esto provoca la confusión entre los documentos. Consideramos que lo adecuado es reconocerlos por el lugar al que se refieren o suponemos que lo hacen, mientras que se confirme mediante un estudio particular.

En las restantes columnas del Cuadro 2 se recogen las siguientes informaciones: fragmentos o partes que lo componen, folios, dimensiones, número en catálogos previos y ubicación actual. El resultado que mostramos es fruto del análisis que hemos mostrado brevemente en este trabajo y de la revisión de la bibliografía disponible. Entre otras cosas, hemos primado la unión de fragmentos y también de formatos distintos que se refieren a un mismo lugar. Cabe señalar que aun así podría plantearse que el de hoja suelta tiene suficiente relevancia para dejarlo aparte. En este caso, somos de la opinión de que, sin un análisis más profundo, incluso lo deberíamos eliminar del censo. Por ello, de momento hemos preferido simplemente agregarlos al Techialoyan del lugar cuando lo tenemos.

Esperamos que esta propuesta contribuya a facilitar nuevos estudios sobre el corpus, evitando hablar de la existencia de más de 40 o 50 documentos. Ahora bien, se debe pensar en una nueva categoría para aquellos que son copias, pues pensamos que estos no presentan muchas de las características de los Techialoyan pero tienen un gran interés. Por ello, presentamos el Cuadro 3 donde recogemos, junto a los «perdidos», estos documentos, indicando qué conservamos de ellos.

\section{Conclusiones}

Los Techialoyan constituyen un conjunto singular dentro de los códices mesoamericanos por diversos motivos. Uno de ellos es la época en que se crearon, pero también es importante el porqué. Para comprender mejor este corpus es necesario avanzar tanto en el estudio individual como en el del grupo, sobre todo respecto a su contexto de creación. Son muchos los investigadores que actualmente se dedican a analizarlos, directa o indirectamente (Wood 1998 y 2007; Martínez García 2007; Castañeda 2009) pero 
nos parecía sorprendente, tras revisar el catálogo más actualizado (Noguez y Martínez 2009), que su número podía estar por encima de la realidad. Es por ello que presentamos este trabajo y llegamos a la conclusión de que el número sería de 34.

Nuestro resultado es producto de varias acciones. En primer lugar, planteamos la necesidad de unir fragmentos conocidos de un mismo códice, aunque estén en distintos lugares. En segundo, creemos que tal vez se debería considerar, cuando existen, mapa y libro europeo u otro formato, como un solo códice y no como dos. También cabe la posiblidad de contemplar los mapas como un grupo particular. En tercero, las copias no constituyen un documento en sí por el momento, sino que deberían ser consideradas como algo separado e incluso distinguir entre diversos tipos. En cuarto, aquellos códices que sólo se conocen por referencias vagas no deben incluirse en el recuento. Este nuevo censo lo hemos recogido en un nuevo listado (véase Cuadro 2) en el que presentamos los documentos por orden alfabético. Los nombramos por el apelativo náhuatl del lugar al que se refieren y eliminamos los números o letras para evitar confusiones con listados anteriores. Además, hemos indicado, cuando es necesario, cuáles son los fragmentos que componen el códice, respetando en este caso la numeración previa que tenían.

Una última reflexión sería si habría que contemplar otros documentos como el Códice de Ayotzinco (BnF, Mexicain 84), cuyo estilo pictórico guarda ciertas similitudes con los Techialoyan, aunque está pintado sobre papel europeo sin filigrana y el contenido parece centrarse en una sucesión de gobernantes. Por ello, pensamos que tal vez fue una copia o se inspiró en algún Techialoyan, pues seguramente se elaboró en el mismo taller.

Finalmente queremos recordar que el Códice García Granados no puede incluirse en el censo de los Techialoyan porque no cumple con las características del corpus, aunque pudo estar ligado con el origen del mismo. Así, para J. J. Batalla (2008: 218; 2011: 260) pudo ser el origen del estilo. Por tanto, a pesar de que lo hayamos excluido del listado de este corpus, no pretendemos que se olvide en el estudio general del mismo, pero deseamos dejar claro que no es uno de ellos. 


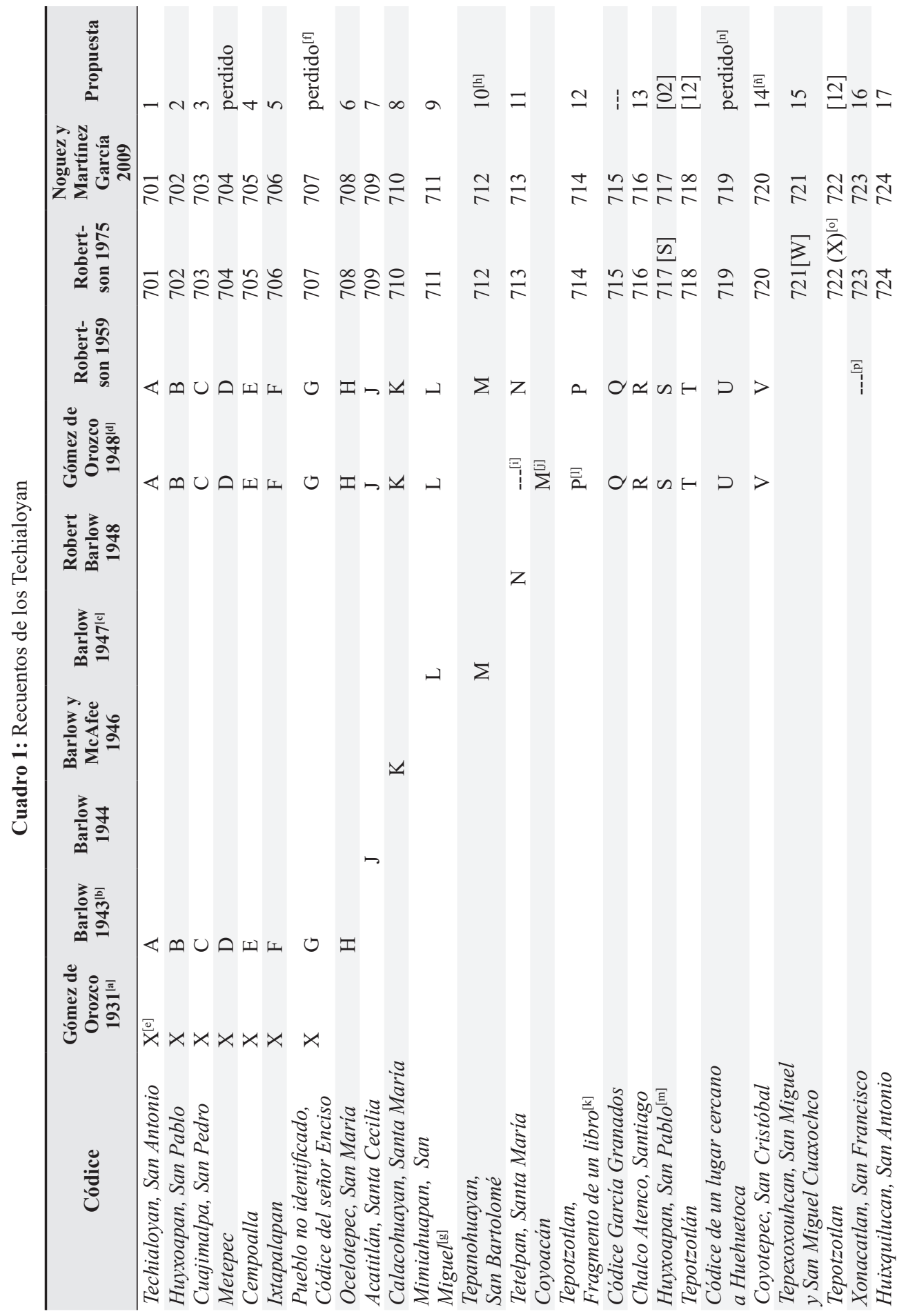




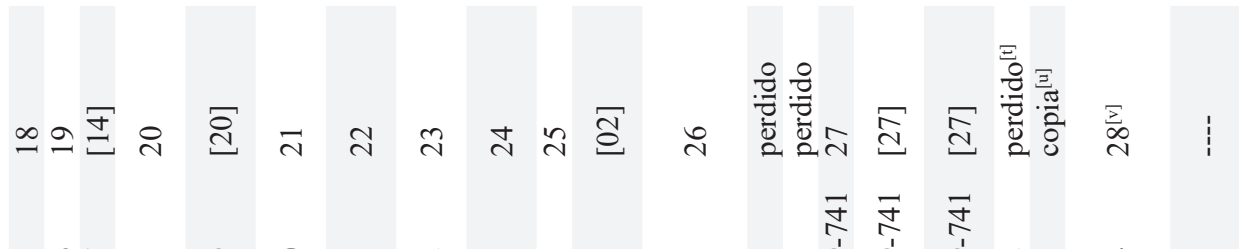

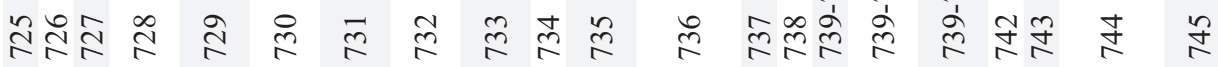

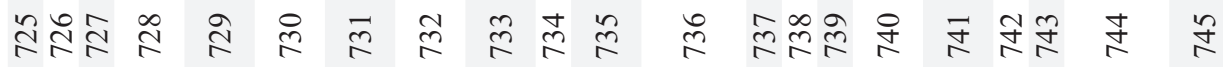

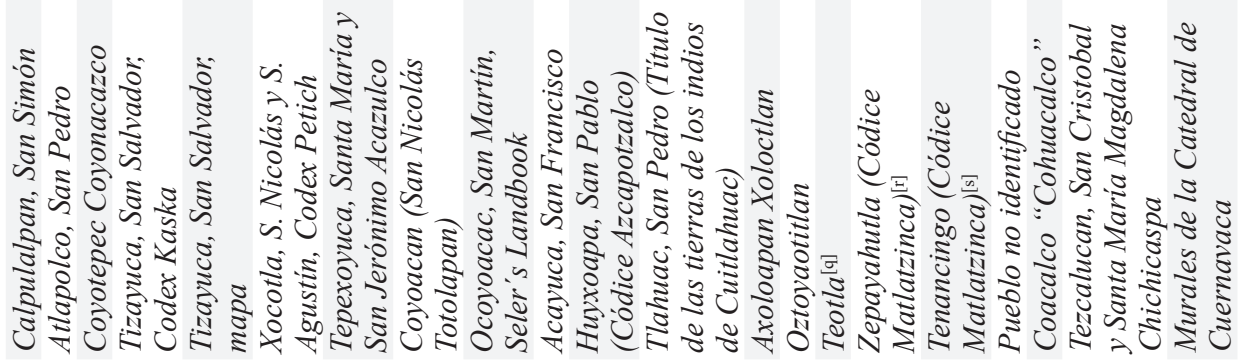




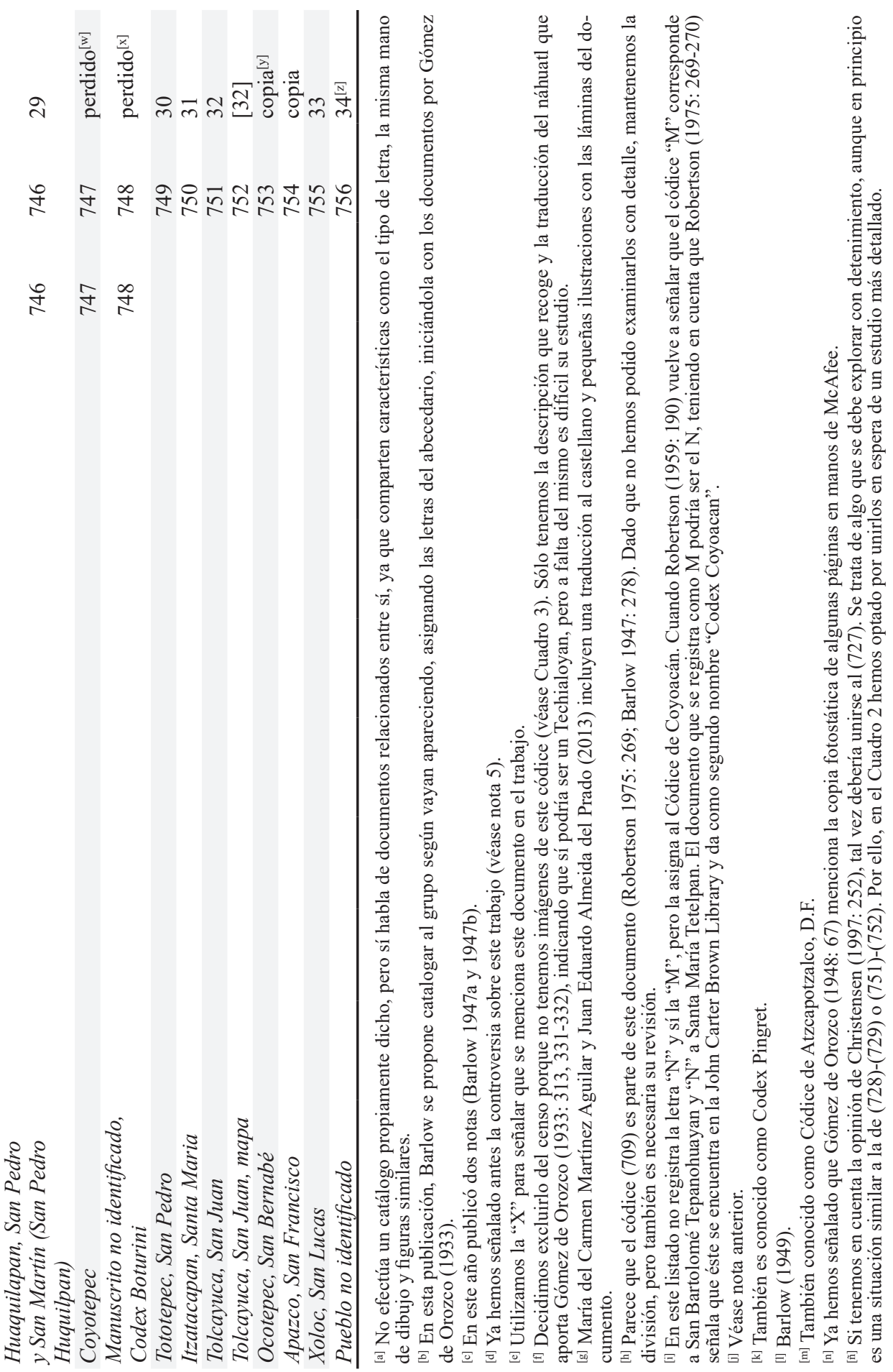




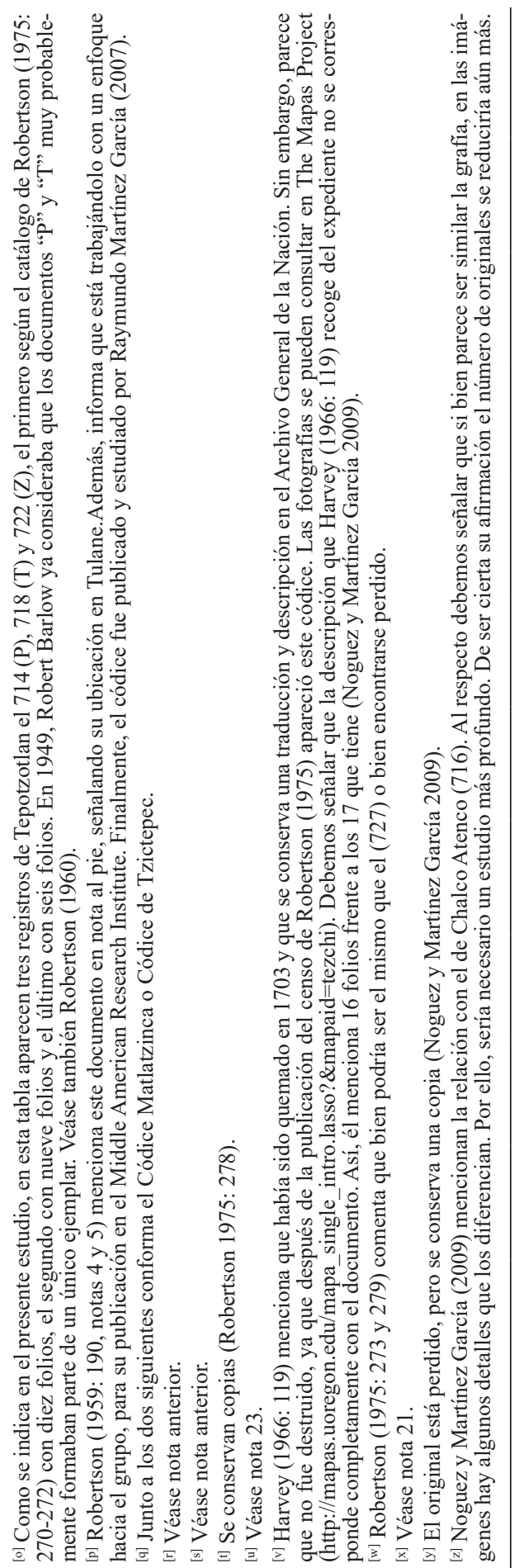




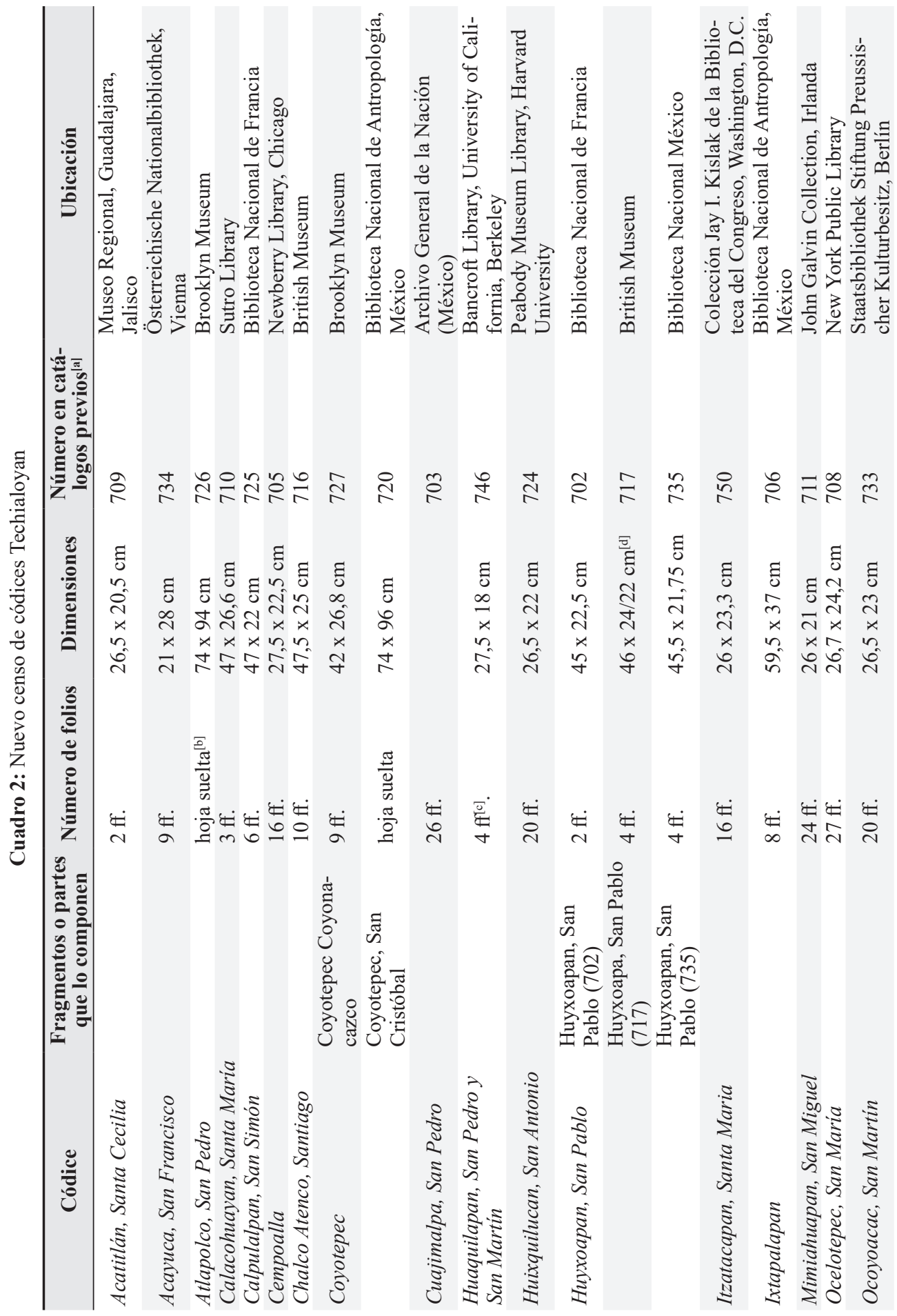




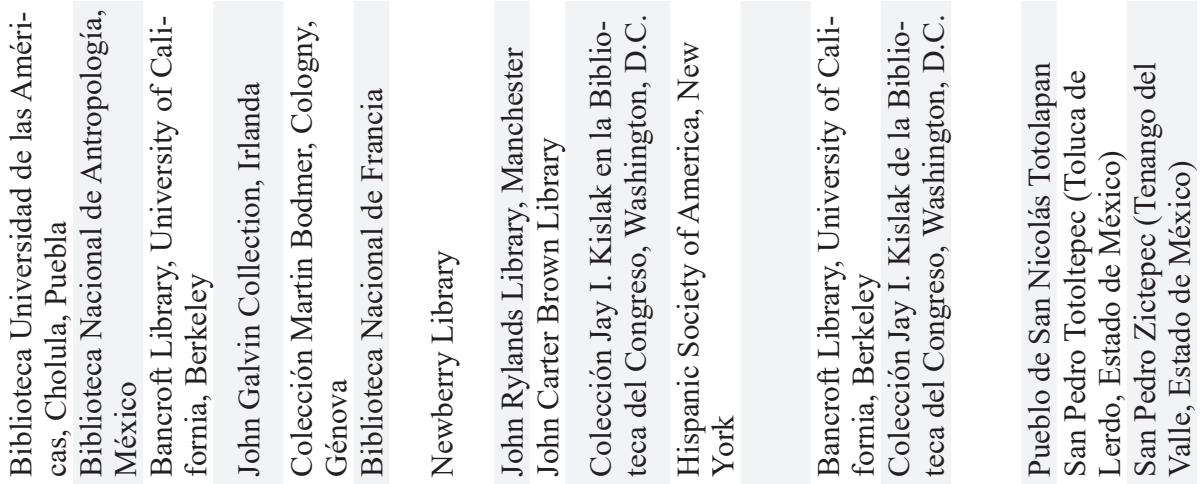

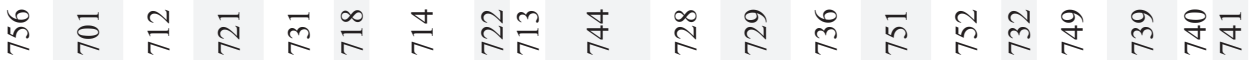

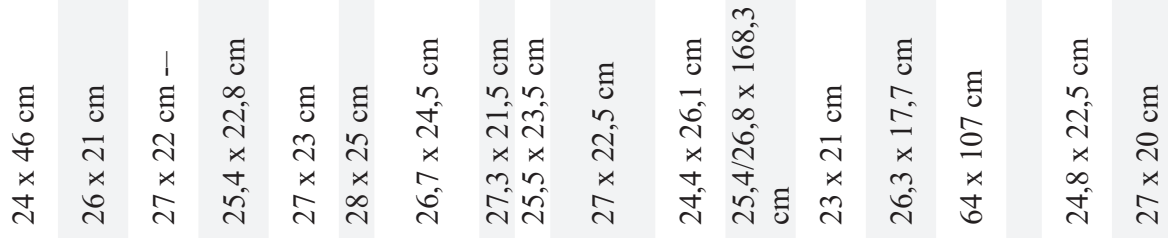

ய

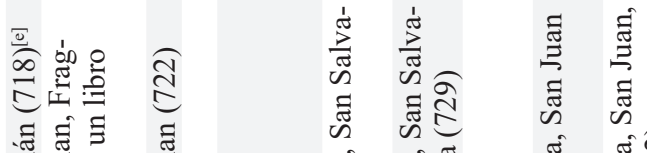

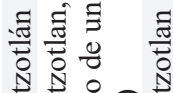

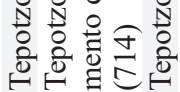

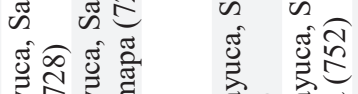

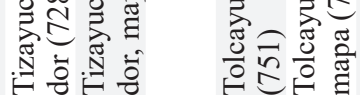

辛昰

六 $\stackrel{\pi}{*}:$

를

菅 芯氙
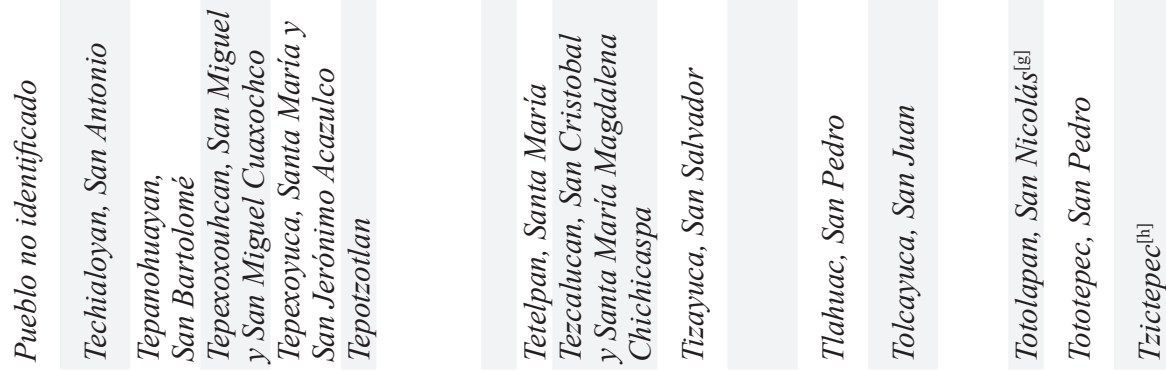


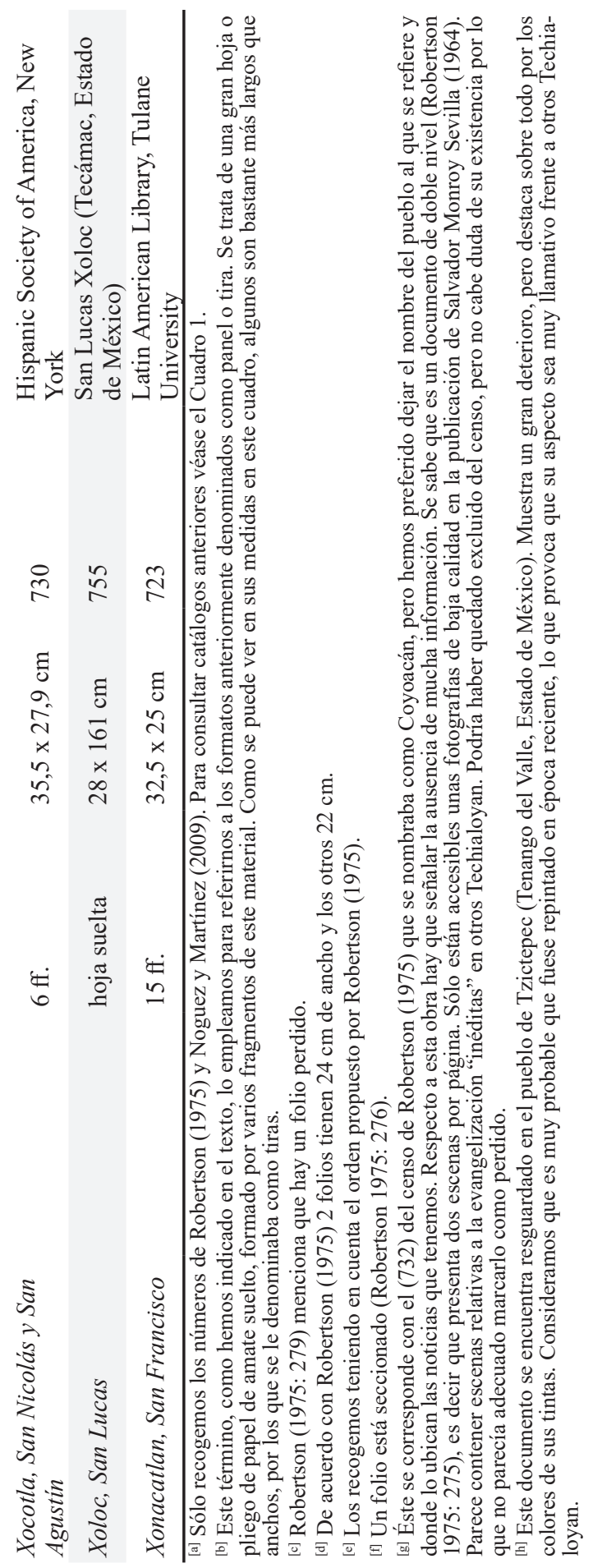




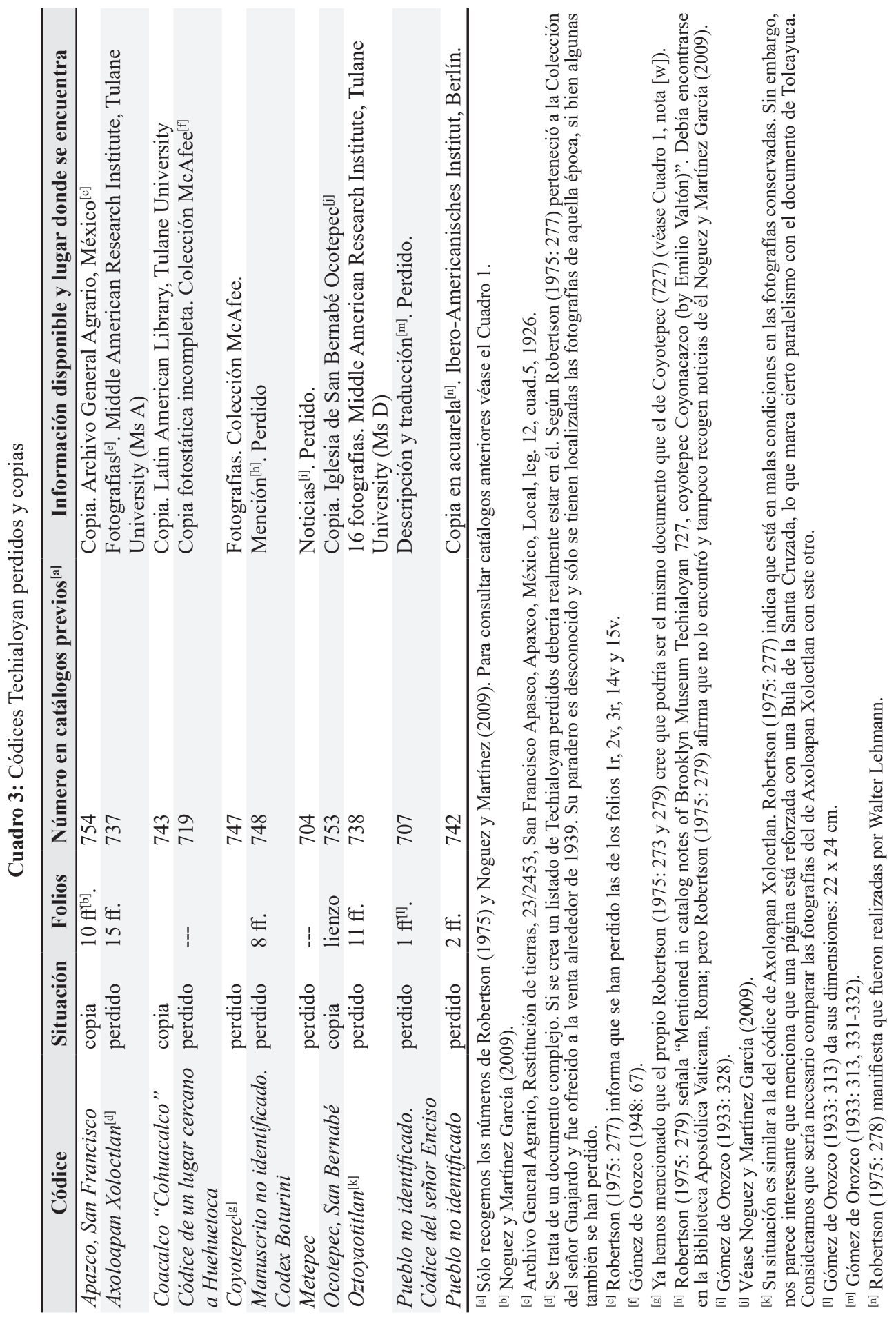




\section{Referencias bibliográficas}

BARLOW, R. H.

1943 «The Techialoyan Codices: Codex H (Códex of Santa María Ocelotepec)». Tlalocan 1 (2): 161-162.

1944 «The Techialoyan Codices: Codex J (Codex of Santa Cecilia Acatitlan)». Tlalocan 1 (3): 232-234.

1947a «The Techialoyan Codices: Codex L (Codex of San Miguel Mimiahuapan)». Tlalocan 2 (3): 276.

$1947 b$ «The Techialoyan Codices: Codex M (Codex of San Bartolomé Tepanohuayan)». Tlalocan 2 (3): 277-278.

1948 «The Techialoyan Codices: Codex N (Codex of Santa María Tetelpan)». Tlalocan 2 (4): 383-384.

1949 «The Techialoyan Codices: Codex P (Codex from the Vicinity of Tepoztlan, Mexico)». Tlalocan. 3 (1): 83.

1994 «Lista tentativa de los códices Techialoyan» [1948], en Obras completas de Robert H. Barlow, Jesús Monjarás Ruiz, Elena Limón y María del Cruz Paillés, eds.,vol. 5, pp. 391-396. México: Universidad de las Américas - Instituto Nacional de Antropología e Historia.

BARlow, R. H. y Byron McAFFE

1946 «The Techialoyan Codices: Codex K (Codex of Santa María Calacohuayan)». Tlalocan II (2): 184-185.

Batalla Rosado, Juan José

2005 «Códices indianos del siglo XVI. La pervivencia de la escritura indígena tradicional», en IV Jornadas Cientificas sobre documentación de Castilla e Indias en el siglo XVI, pp. 11-24. Madrid: Universidad Complutense de Madrid.

2006 «Las falsificaciones de Códices Mesoamericanos», en Escrituras silenciadas en la época de Cervantes, Manuel Casado Arboniés, Antonio Castillo Gómez, Paulina Numhauser y Emilio Sola, eds., pp. 355-377. Alcalá de Henares: Servicio de Publicaciones de la Universidad de Alcalá.

2008 El Códice Borgia. Una guía para un viaje alucinante por el inframundo. Madrid: Biblioteca Apostólica Vaticana - Testimonio Compañía editorial.

2011 «La importancia de la escritura en Mesoamérica. Los códices o libros pintados», en Mitificadores del pasado, falsarios de la Historia: Historia medieval, moderna y de América, José Antonio Munita Loinaz, ed.,pp. 203-254. Bilbao: Universidad del País Vasco.

BÉLIGAND, Nadine

1993 Códice Techialoyan de San Antonio Techialoyan. México: Gobierno del Estado de México - Instituto Mexiquense de Cultura.

Castañeda de la Paz, María

2009 «Filología de un 'corpus' pintado (siglos XVI-XVIII): de códices, techialoyan, pinturas y escudos de armas». Anales del Museo de América 17: 78-95.

Christensen, Alexander F.

1997 «The codex of San Cristóbal Coyotepec and its ramifications for the production of techialoyan manuscripts». Estudios de Cultura Náhuatl 27: 247-266.

DRAE

2012 Diccionario de la Real Academia Española, 22ª edición, versión digital disponible en http://www.rae.es, con acceso el 14/12/2014. 
FANE, Diana

1996 Converging Cultures: Art and Identity in Spanish America. Brooklyn: Brooklyn Museum Bookshop.

GARIBAY, Angel María

1992 Códice de Metepec Estado de México [1949]. México: H. Ayuntamiento Constitucional de Metepec 1991-1993.

Glass, John B.

1975a «A Survey of Native Middle American Pictorial Manuscripts», en Guide to Ethnohistorical Sources, Handbook of Middle American Indians, vol. 14, Howard F. Cline, ed., pp. 3-80. Austin: University of Texas Press.

1975b «A Census of Middle American Testerian Manuscripts», en Guide to Ethnohistorical Sources, Handbook of Middle American Indians, vol. 14, Howard F. Cline ed., pp. 281-296. Austin: University of Texas Press.

1975c «A Catalog of Falsified Middle American Pictorial Manuscripts», en Guide to Ethnohistorical Sources, Handbook of Middle American Indians, vol. 14, Howard F. Cline, ed., pp. 297-310. Austin: University of Texas Press.

GLASS, John B. y Donald RoBERTSON

1975 «A Census of Native Middle American Pictorial Manuscripts», en Guide to Ethnohistorical Sources, Handbook of Middle American Indians, vol. 14, Howard F. Cline, ed., pp. 81-252. Austin: University of Texas Press.

Gómez de Orozco, Federico

1933 «El Códice de San Antonio Techialoyan estudio histórico-paleográfico». Anales del Museo Nacional de Arqueología, Historia y Etnografía 8: 311-332.

1948 «La pintura indio europea de los Códices Techialoyan». Anales del Instituto de Investigaciones Estéticas 16: 57-67.

HARVEY, Herbert R.

1966 «The Codex of San Cristóbal and Santa María: A False Techialoyan». Tlalocan 5 (2): 119-124.

1986 «Techialoyan Codices: Seventeenh-Century Indian Land Titles in Central Mexico», en Handbook of Middle American Indians, sup. 4, Howard F. Cline ed., pp. 153-164. Austin: University of Texas Press.

1993 Códice Techialoyan de Huixquilucan, Estado de México. México: El Colegio Mexiquense, A.C.

López Caballero, Paula

2003 Los Títulos Primordiales del Centro de México. México: CONACULTA.

Martínez Aguilar, María del Carmen y Juan Eduardo Almeida del Prado

2013 «El Códice Techialoyan de San Miguel Mimiapan». Alegatos 83: 315-336.

Martínez García, Raymundo César

2007 Códice de San Francisco Xonacatlan. México: El Colegio Mexiquense, A.C.

2011 «Los códices del grupo Techialoyan», en Ciclo de Conferencias 2011. Arqueología y Etnohistoria de Mesoamérica. Zinacantepec: El Colegio Mexiquense. Documento electrónico, http://www.cmq.edu.mx/index.php/difusionmen/ videoconferencias, con acceso el 14/12/2014.

Molina, fray Alonso de

2013 Vocabulario en lengua castellana/mexicana y mexicana/castellana [1571]. México: Editorial Porrúa. 
Monroy SEvilla, Salvador

1964 Códice de San Nicolás Totolapan. México: Departamento de Asuntos Agrarios y colonización / Museo Agrario.

Noguez, Xavier

1992 Codice Techialoyan Garcia Granados. Zinacantepec: El Colegio Mexiquense, A.C.

1999 Códice Techialoyan de San Pedro Tototepec. México: El Colegio Mexiquense, A.C.

Noguez, Xavier y Raymundo Martínez García

2009 «The Techialoyan Pictorials», en Wiki Filología. Documento electrónico, http://132.248.101.214/wikfil/index.php/Techialoyan, con acceso el 14/12/2014.

QUARITCH, Bernard

1890 Mexican Picture-Chronicle of Cempoallan and other States of the Empire of Aculhuacan. Londres.

RoBERTSON, Donald

1959 Mexican Manuscript Painting of the Early Colonial Period: The Metropolitan Schools. New Haven: Yale Universty Press.

1960 «The Techialoyan Codex of Tepotzotlan: Codex X, Rylands Mexican Manuscript-1». Bulletin of the John Rylands Library 43 (3): 109-130.

1975 «Techialoyan Manuscripts and Paintings with a Catalog», en Guide to Ethnohistorical Sources, Handbook of Middle American Indians, vol. 14, Howard F. Cline, ed., pp. 253-265. Austin: University of Texas Press.

WIKI-FILOLOGÍA

s.f. $\quad$ http://132.248.101.214/wikfil/index.php/Portada, con acceso el 14/12/2014.

Wood, Stephanie

1998 «El problema de la historicidad de Títulos y los códices del grupo Techialoyan», en De tlacuilos y escribanos: estudios sobre documentos indígenas coloniales del centro de México, Xavier Noguez Ramírez y Stephanie Wood, eds., pp. 167-221. México: El Colegio Mexiquense - El Colegio de Michoacán.

2007 «The Techialoyan Codices», en «Sources and Methods for the Study of Postconquest Mesoamerican Ethnohistory». Eugene, Ore.: Wired Humanities Project, University of Oregon. Documento electrónico, http://whp.uoregon.edu/Lockhart/ Wood.pdf, con acceso el 14/12/2014. 